\title{
A novel revision surgery for treatment of cervical ossification of the posterior longitudinal ligament after initial posterior surgery: preliminary clinical investigation of anterior controllable antidisplacement and fusion
}

Hai-Dong Li ${ }^{1 *} \mathbb{D}$, Qiang-Hua Zhang ${ }^{1}$, Shi-Tong Xing ${ }^{1}$, Ji-Kang Min ${ }^{1}$, Jian-Gang Shi ${ }^{2}$ and Xiong-Sheng Chen ${ }^{2}$

\begin{abstract}
Background: Cervical ossification of the posterior longitudinal ligament (OPLL) is a progressive disease. Posterior decompression surgery is reported to be an effective and comparatively safe procedure with few complications for treatment of patients with myelopathy caused by OPLL. However, some patients require revision surgery because of late neurological deterioration due to OPLL progression or kyphotic changes in cervical alignment. This study reports preliminary clinical results of anterior controllable antidisplacement and fusion (ACAF), a novel revision surgery after initial posterior surgery for OPLL.

Methods: From January 2017 to June 2018, ten patients with cervical OPLL who underwent ACAF revision surgery after initial posterior surgery were included in this study. The mean age was $62.1 \pm 8.0$ years (52-78), and the mean interval between initial posterior surgery and revision was $78.0 \pm 48.2$ months (5-180). The Japanese Orthopaedic Association (JOA) scales, Neck Disability Index (NDI), visual analog scale (VAS), and surgical complications were recorded.

Results: The mean surgery time was $179.3 \pm 41.8 \mathrm{~min}$ (120-240), and the mean blood loss was $432.5 \pm 198.3 \mathrm{ml}$ (225-850). The patients were followed up for at least 12 months. The JOA scores improved from $8.7 \pm 2.8$ to $13.4 \pm 2.4$; the mean improvement rate was $59.9 \% \pm 16.1 \%$. Postoperative NDI and VAS scores were $13.3 \pm 3.7$ and $2.0 \pm 1.6$, respectively, and were significantly improved compared to those before the procedure $(P<0.05)$. Cervical lordosis improved from $3.8 \pm 4.3^{\circ}$ to $17 \pm 4.6^{\circ}$ after revision surgery. There was only one instance of cerebrospinal fluid (CSF) leakage; no instances of postoperative hematoma, C5 root palsy, or hoarseness occurred.

Conclusions: The present study demonstrates that excellent postoperative outcomes can be achieved with the ACAF technique for revision treatment of OPLL. Though further study is required to confirm the conclusion, this novel technique has the potential to serve as an alternative surgical technique for revision treatment of OPLL.
\end{abstract}

Keywords: Cervical, Ossification of the posterior longitudinal ligament, Revision, Antidisplacement

\footnotetext{
*Correspondence: hd_lee2008@163.com

'Department of Spine Surgery, First People's Hospital affiliated to the Huzhou

University Medical College, 158\# GuangChang Hou Road, Huzhou, Zhejiang

Province, China

Full list of author information is available at the end of the article
}

(c) The Author(s). 2018 Open Access This article is distributed under the terms of the Creative Commons Attribution 4.0 International License (http://creativecommons.org/licenses/by/4.0/), which permits unrestricted use, distribution, and

reproduction in any medium, provided you give appropriate credit to the original author(s) and the source, provide a link to the Creative Commons license, and indicate if changes were made. The Creative Commons Public Domain Dedication waiver (http://creativecommons.org/publicdomain/zero/1.0/) applies to the data made available in this article, unless otherwise stated. 


\section{Background}

Ossification of the posterior longitudinal ligament (OPLL) is frequently related to cervical myelopathy [1]. Minimally symptomatic patients can be treated conservatively; however, patients with progressive myelopathy require surgical treatment [2, 3]. Several options for treating cervical OPLL have been established involving anterior and posterior surgery. Anterior decompression surgery can directly decompress the cervical spinal cord by removing the ossified ligament and always results in better outcomes and neurological improvement [4, 5]. However, it is considered technically demanding and is associated with serious complications, such as intraoperative neural injury, symptomatic cerebrospinal fluid leakage (CSF), graft dislodgment, and adjacent segment disease $[6,7]$.

The two typical posterior methods, laminoplasty and laminectomy, are reported as comparatively safe procedures with few complications for the treatment of OPLL $[8,9]$. They decompress the spinal cord indirectly, depending on the backward shift of the cervical spinal cord [10]. Long-term outcomes of posterior surgery seem to be favorable, although it is criticized for C5 nerve root palsy, progression of OPLL, and poor cervical lordosis $[11,12]$. In cases with poor cervical lordosis or progressive OPLL lesion, neurological improvement is always diminished [8, 13]. Therefore, after cervical posterior surgery, some patients require revision surgery due to late neurological deterioration [14]. Revision surgery is challenging, perhaps because of a combination of progressive kyphosis, segmental instability, massive progressive OPLL, and dural ossification [15].

Sun et al. first described the anterior controllable antidisplacement and fusion (ACAF) technique for the treatment of multilevel severe ossification of the posterior longitudinal ligament with myelopathy [16]. The goal of ACAF is to isolate and "actively transport" residual osteophytes or ossification to restore the space of the spinal canal and thus achieve direct decompression of the neural elements with their location unchanged. The purpose of this study was to investigate the clinical results of ACAF as a revision surgery for cervical OPLL after initial posterior surgery.

\section{Methods}

\section{Patient population}

We conducted a retrospective study of ACAF as a revision surgery performed after initial posterior surgery for cervical myelopathy due to OPLL. From January 2017 to June 2018, ten patients who underwent ACAF revision surgery were identified and included in this study. Follow-up was conducted in all patients for at least 12 months. Patients with severe osteoporosis (WHO criteria), pre-existing spinal deformity, cervical spine trauma, spinal infection, or chronic systemic illness were excluded from the study. This study was approved by the Ethics Committee of the authors' affiliated institutions, and all the patients signed an informed consent document.

\section{Radiographic assessment}

Based on preoperative radiographic findings, OPLL of the cervical spine was classified into three types: continuous, segmental, or mixed [15]. The K-line connects the midpoints of the spinal canal at $\mathrm{C} 2$ and $\mathrm{C} 7$ on neutral lateral radiographs. When anterior compression of the OPLL exceeds this line, the K-line is defined as negative [16]. Cervical lordosis was measured as the angle between a line parallel to the posterior aspect of the $\mathrm{C} 2$ vertebral body and that of the $\mathrm{C} 7$ body. Patients were also evaluated radiographically with plain and dynamic cervical spinal radiographs at 3 and 6 months postoperatively and every 6 months thereafter. Pseudarthrosis was defined as an interspinous motion of $>1 \mathrm{~mm}$ on dynamic flexion-extension images.

\section{Clinical assessment}

The Japanese Orthopaedic Association (JOA) scores , visual analog score (VAS), and Neck Disability Index (NDI) were used to measure neck pain, arm pain, and the degree of disability. The improvement rate (IR) of neurologic function was calculated as IR $=$ (postoperative JOA score - preoperative JOA score/17 - preoperative JOA score)/ $100 \%$. The surgical outcome was defined using the IR as follows: excellent (IR $\geq 75 \%$ ), good (75\% > IR $\geq 50 \%$ ), fair ( $50 \%>\mathrm{IR} \geq 25 \%)$, and poor (IR $<25 \%)$.

\section{Surgical technique}

After general endotracheal anesthesia, the patient was placed in a supine position appropriately padded under the shoulders and neck. Neurophysiologic monitoring, such as somatosensory-evoked potentials (SSEPs), was utilized to predict the neurologic deficit during the operation. The exposure was obtained through a Smith-Robinson approach on the right side. First, discectomies of the involved levels were performed. In the cephalad and caudal levels, the posterior longitudinal ligament was resected to facilitate later hoisting of the vertebrae-OPLL complex (VOC). Then, resection of the anterior vertebral bodies of the VOC was performed using a high-speed burr; third, the intervertebral cages and anterior cervical plate were installed. Fourth, bilateral troughs were created along the widest edge of the OPLL. We used a 2-mm high-speed burr to thin the corticocancellous bone first and 1-mm Kerrison rongeurs to remove the posterior vertebral wall on the bottom of the troughs. Finally, the VOC was hoisted by gradually tightening with screws. An illustration of the procedure is shown in Fig. 1. Autogenous bone pieces were grafted 


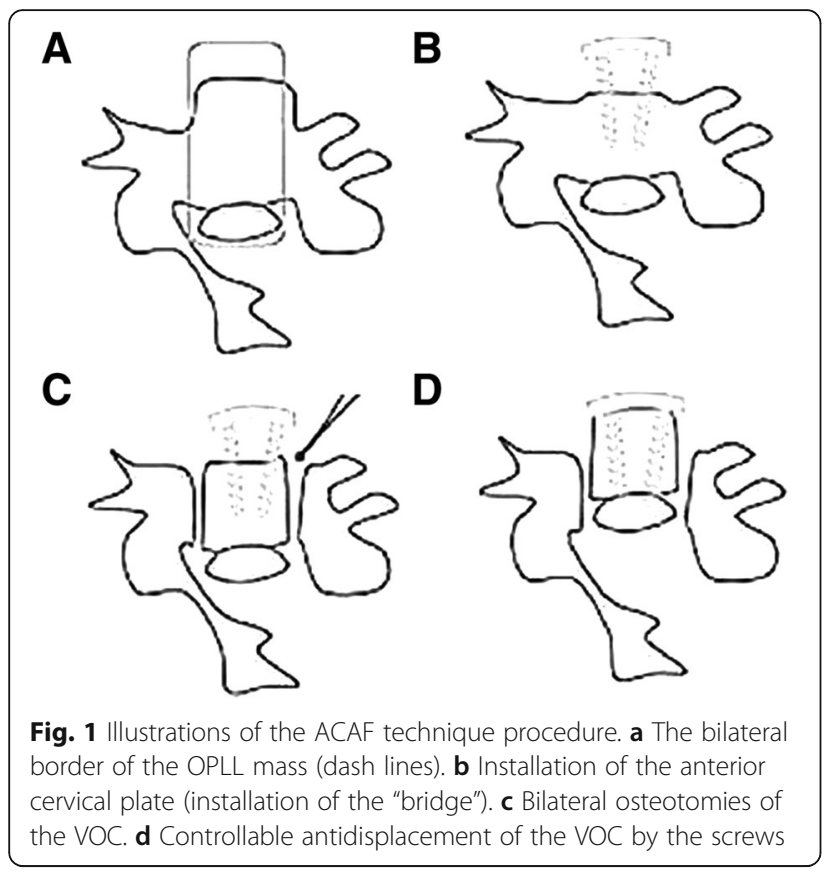

into the bilateral troughs to obtain further fusion. A hard cervical brace was routinely used postoperatively for 3 months.

\section{Statistical analysis}

Statistical analysis was performed using SPSS 16.0. Preoperative and postoperative data such as JOA, VAS, and NDI scores were compared using paired $t$ tests. The level of significance was set at $P<0.05$.

\section{Results}

The patient demographic data are shown in Table 1 . According to physical and radiological findings just before revision surgery, we considered the major reasons for neurological deterioration to be anterior spinal cord compression due to residual OPLL progression and local kyphosis.

\section{Clinical and radiographic results}

The mean operative time in this group was $179 \mathrm{~min}$ (range 120-240 min). The mean intraoperative blood loss was $432 \mathrm{ml}$ (range $225-850 \mathrm{ml}$ ). The mean JOA score was $8.7 \pm 2.8$ (range $5-14$ ) preoperatively and 13.4 \pm 2.4 (range 9-16) after the ACAF surgery $(P<0.05)$. The average IR was $59.9 \pm 16.1 \%$. Two (20\%) patients were graded as excellent, six $(60 \%)$ as good, and two $(20 \%)$ as fair. The mean VAS score decreased from $4.5 \pm$ 1.6 (range 2-7) preoperatively to $2.0 \pm 1.6$ (range $0-5$ ) $(P<0.05)$. The NDI decreased from $24.4 \pm 10.0$ (range $10-40)$ at the preoperative assessment to $13.3 \pm 3.7$ (range $8-20)(P<0.05)$. The postoperative cervical lordosis was $17 \pm 4.6^{\circ}$, which was much better than it was
Table 1 Summary of patient demographics and the results of revision ACAF after initial posterior surgery for cervical OPLL

\begin{tabular}{|c|c|}
\hline Variable & Value \\
\hline \multicolumn{2}{|l|}{$\overline{\text { Sex }}$} \\
\hline Male & 6 \\
\hline Female & 4 \\
\hline Age & $62.1 \pm 8.0(52-78)$ \\
\hline \multicolumn{2}{|l|}{ Previous pst op } \\
\hline Laminectomy & 4 \\
\hline Laminoplasty & 4 \\
\hline Decompression & 2 \\
\hline $\begin{array}{l}\text { Mean interval btwn initial op and revision, } \\
\text { months }\end{array}$ & $78.0 \pm 48.2(5-180)$ \\
\hline \multicolumn{2}{|l|}{ Type of the ossification } \\
\hline Continuous & 4 \\
\hline Segmental & 3 \\
\hline Mixed & 3 \\
\hline \multicolumn{2}{|l|}{ K-line } \\
\hline Minus & 6 \\
\hline Plus & 4 \\
\hline Mean op time, min & $179.3 \pm 41.8(120-240)$ \\
\hline Mean blood loss, ml & $432.5 \pm 198.3(225-850)$ \\
\hline \multicolumn{2}{|l|}{ Complications, number of patients } \\
\hline CSF leakage & 1 \\
\hline C5 palsy & 0 \\
\hline Postoperative hematoma & 0 \\
\hline Implant complication & 0 \\
\hline
\end{tabular}

Pst posterior, op operation, btwn between Values are expressed as the mean \pm SD (range)

before. No patients demonstrated a progression of kyphotic deformity at subsequent follow-ups (all results are shown in Table 2). Images of typical cases are shown in Figs. 2 and 3.

\section{Complication}

There was only one case of intraoperative CSF leakage. The leakage happened when the posterior longitudinal ligament of the cephalad level was resected. Fortunately, it was a small hole and was healed using a sponge and elastic bandage. There were no occurrences of postoperative hematoma or C5 root palsy. No instrument failure was observed during the follow-up.

\section{Discussion}

The gold standard surgical treatment for cervical myelopathy caused by OPLL remains controversial. The choice of surgical method for initial or revision surgery should depend on the location of spinal cord compression, the sagittal alignment of the cervical spine, and the general health status of the patient $[17,18]$. 
Table 2 Clinical and radiological results of patients

\begin{tabular}{ll}
\hline Item & Value \\
\hline JOA & $8.7 \pm 2.8(5-14)$ \\
Before surgery & $13.4 \pm 2.4(9-16)^{*}$ \\
After surgery & \\
NDI & $24.4 \pm 10.0(10-40)$ \\
Before surgery & $13.3 \pm 3.7(8-20)^{*}$ \\
After surgery & \\
VAS & $4.5 \pm 1.6(2-7)$ \\
Before surgery & $2.0 \pm 1.6(0-5)^{*}$ \\
After surgery & \\
Cervical lordosis $\left(^{\circ}\right)$ & $3.8 \pm 4.3(-7.6$ to -15$)$ \\
Before surgery & $17 \pm 4.6(16 \text { to } 27)^{*}$ \\
After surgery
\end{tabular}

JOA Japanese Orthopaedic Association scores, VAS visual analog score, NDI Neck Disability Index

Values are expressed as the mean $\pm S D$ (range)

${ }^{*} P<0.05$, compared with the data before surgery

The posterior procedure is relatively simple and with low complication rates, and it has been widely used as an initial surgery for cervical OPLL [15]. Though the results of the posterior surgery depend on the backward shift of the cervical spinal cord [5], it has been shown to have the same excellent results as anterior decompression surgery [19, 20]. Relief of symptoms or prevention of symptom progression has been achieved in most patients after surgical decompression of cervical OPLL. However, some patients need revision surgery because of late neurological deterioration [21, 22]. There are two explanations for late deterioration. First, the loss of cervical lordosis or even development of kyphosis is not uncommon after posterior surgery $[23,24]$. Second, OPLL tends to progress more often after cervical laminoplasty or laminectomy than it does after anterior decompression surgery $[22,25]$. The frequency of OPLL progression has been reported to be as high as 70\% [26]. And the mean annual rate of lesion increase was reported as about 3.33\% [27].

When considering revision surgery for patients who have already received posterior decompression surgery, it is impossible to again perform decompression from the posterior aspect. Anterior cervical corpectomy and fusion may be a good choice; however, it is considered technically demanding and is associated with serious complications, such as intraoperative spinal cord injury, symptomatic CSF leakage, adjacent segment disease, and graft dislodgment [5]. Macdonald et al. reported that multilevel anterior cervical corpectomy and fusion carries an approximately $22 \%$ risk of surgical mortality and morbidity, including pneumonia, deep vein thrombosis,

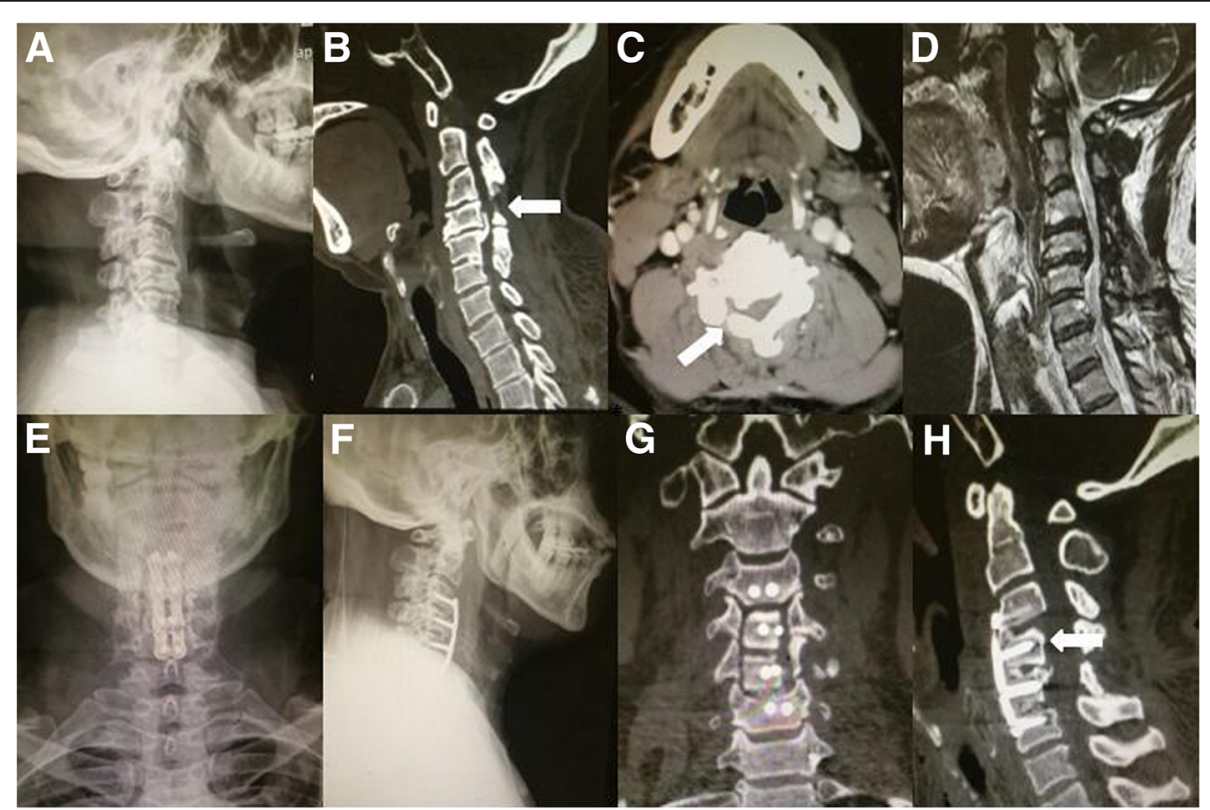

Fig. 2 A revision case of a 59-year-old man 5 years after initial posterior decompression surgery. a The lateral image showed that cervical kyphosis occurred after the initial posterior surgery. b, c The CT scan showed that there was only a window decompressing without fixation in the initial posterior surgery (arrows). $\mathbf{d}$ The MRI showed that the cervical spinal cord of C4-5 was compressed by the OPLL. e, $\mathbf{f}$ The postoperative anterior-posterior and lateral images showed good device positioning and persistent poor cervical lordosis. $\mathbf{g}$, $\mathbf{h}$ The postoperative CT scan showed that the bilateral troughs were created along the widest edge of the OPLL, and we hoisted the VOC by the screws (arrows). We usually used a 2-mm high-speed cutting burr and 1-mm Kerrison rongeurs to remove the posterior vertebral wall on the bottom of the troughs 


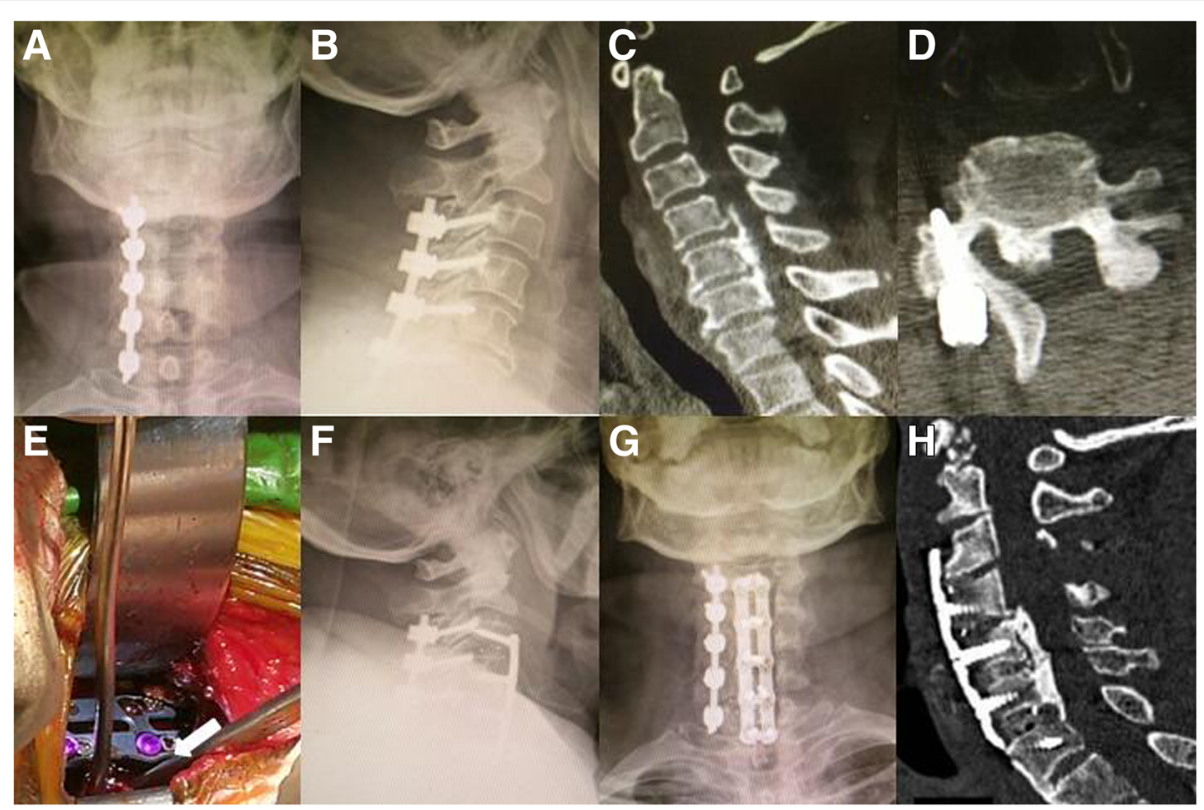

Fig. 3 A revision case of a 61-year-old man 12 months after initial posterior laminectomy. $\mathbf{a}$, b The anterior-posterior and lateral images showed the loss of cervical lordosis after the initial laminectomy. $\mathbf{c}$, $\mathbf{d}$ The $C T$ scan showed that there was a continuous type of OPLL, and only a semilaminectomy with one-sided lateral mass fixation was done in the initial surgery. $\mathbf{e}$ The intraoperative photo showed that after installation of the intervertebral cages and anterior cervical plate, we used 1-mm Kerrison rongeurs to remove the posterior vertebral wall on the bottom of the troughs for isolation of the VOC (arrows). $\mathbf{f}, \mathbf{g}$ The postoperative anterior-posterior and lateral images showed good internal fixation position and improved cervical lordosis. $\mathbf{h}$ The $C T$ scan showed that the VOC was hoisted forward, and the cervical spinal canal was obviously wider than it was before

and death [28]. Odate et al. suggested that the use of anterior compression revision surgery for OPLL must be limited due to the high probability of intraoperative CSF leakage and extremely low improvement rate [15]. In their study, surgery-related complications occurred in $63 \%$ of patients, the main complication being intraoperative CSF leakage (42\%), and the mean improvement rate of the JOA score was only $18 \%$. To minimize the surgical risk of CSF leakage, hemorrhage, and spinal cord injury, Yamaura et al. reported the floating method for the treatment of cervical myelopathy due to OPLL [29]. However, the anterior migration of the OPLL in the floating method is not controlled by the surgeon and owes much to the pressure of the CSF, and approximately $14 \%$ of the cases showed inadequate decompression of the spinal canal due to residual ossification with or without postoperative progression of OPLL.

In our study, we used a novel technique called ACAF as the revision surgery for OPLL. It can isolate and actively transport the OPLL ventrally to restore the space of the spinal canal and thus achieve direct decompression of the neural elements with their location unchanged. In contrast to the floating method, the antidisplacement of the OPLL is achieved by the gradual hoisting force of the anterior plate and screws, with immediate feedback. The anatomical basis for the clinical effect of these cases lies in the direct decompression of the spinal cord and nerve roots. Bilateral osteotomies of the vertebrae with a width of $18 \mathrm{~mm}$ give enough decompression to the bilateral nerve roots. In this study, the mean improvement rate of the JOA scores was $59.9 \%$. There was only one surgery-related complication (10\%) in the study patients. In that case, there was severe adhesion between the dura mater and the ossified posterior longitudinal ligament, and the CSF leak happened when resecting the posterior longitudinal ligament of the cephalad level. Fortunately, it was healed by a sponge and elastic bandage.

\section{Limitation}

This study was only a retrospective study with a small sample size to explore a new revision method for multilevel cervical OPLL after initial posterior surgery. Prospective multiple-center studies, long-term data, and a control group are needed to confirm the result.

\section{Conclusion}

The present study demonstrates that excellent postoperative outcomes can be achieved with the use of ACAF. Though further study is required to confirm the conclusion, this novel technique has the potential to serve as an alternative revision technique for cervical OPLL after initial posterior surgery. 


\section{Acknowledgements}

We express deep thanks to Dr. Jian-Gang Shi and Xiong-Sheng Chen for their technical support.

\section{Availability of data and materials}

The datasets analyzed during the current study are available from the corresponding author on reasonable request.

\section{Authors' contributions}

HDL had full access to all of the data in the study and took responsibility for the integrity of the data and the accuracy of the data analysis. All authors meet all three of the requirements for authorship. QHZ, STX, and JKM were highly involved in the planning and execution of this study. Furthermore, JGS and XSC were highly involved in the acquisition of data and in the process of data interpretation. All authors read and approved the final manuscript.

\section{Ethics approval and consent to participate}

This study had been approved by the Ethics Committee of the authors' affiliated institutions, and all the patients signed the informed consent.

\section{Consent for publication}

Consent for publication, including photographic images, was provided by the participants at the time of enrollment.

\section{Competing interests}

The authors declare that they have no competing interests.

\section{Publisher's Note}

Springer Nature remains neutral with regard to jurisdictional claims in published maps and institutional affiliations

\section{Author details}

'Department of Spine Surgery, First People's Hospital affiliated to the Huzhou University Medical College, 158\# GuangChang Hou Road, Huzhou, Zhejiang Province, China. ${ }^{2}$ Department of Spine Surgery, Changzheng Hospital, 415\# Fengyang Road, Huangpu District, Shanghai, China.

Received: 14 June 2018 Accepted: 20 August 2018

Published online: 29 August 2018

\section{References}

1. Matsunaga S, Sakou T. Ossification of the posterior longitudinal ligament of the cervical spine: etiology and natural history. Spine. 2012;37:E309-14.

2. Iwasaki M, Okuda S, Miyauchi A, Sakaura H, Mukai Y, Younenobu K, Yoshikawa $\mathrm{H}$. Surgical strategy for cervical myelopathy due to ossification of the posterior longitudinal ligament: part I: clinical results and limitations of laminoplasty. Spine (Phila Pa 1976). 2007;32:647-53.

3. Iwasaki M, Okuda S, Miyauchi A, Sakaura H, Mukai Y, Younenobu K, Yoshikawa H. Surgical strategy for cervical myelopathy due to ossification of the posterior longitudinal ligament. Part 2: advantages of anterior decompression and fusion over laminoplasty. Spine (Phila Pa 1976). 2007;32:654-60.

4. Kim B, Yoon DH, Shin HC, Kim KN, Yi S, Shin DA, Ha Y. Surgical outcome and prognostic factors of anterior decompression and fusion for cervical compressive myelopathy due to ossification of the posterior longitudinal ligament. Spine J. 2015;15:875-84

5. Wang $S$, Xiang $Y$, Wang $X$, Li H, Hou Y, Zhao H, Pan X. Anterior corpectomy comparing to posterior decompression surgery for the treatment of multilevel ossification of posterior longitudinal ligament: a meta-analysis. Int J Surg. 2017:40:91-6

6. Tani T, Ushida T, Ishida K, lai H, Noguchi T, Yamamoto $H$. Relative safety of anterior microsurgical decompression versus laminoplasty for cervical myelopathy with a massive ossified posterior longitudinal ligament. Spine (Phila Pa 1976). 2002;27:2491-8.

7. Liu T, Xu W, Chen T, Yang HL. Anterior versus posterior surgery for multilevel cervical myelopathy, which one is better? A systematic review. Eur Spine J. 2011;20:224-35.

8. Iwasaki M, Kawaguchi Y, Kimura T, Yonenobu K. Long-term results of expansive laminoplasty for ossification of the posterior longitudinal ligament of the cervical spine: more than 10 years follow up. J Neurosurg. 2002;96(2 Suppl):180-9.
9. Lee SE, Chung CK, Jahnq TA, Kim HJ. Long-term outcome of laminectomy for cervical ossification of the posterior longitudinal ligament. J Neurosurg Spine. 2013;18:465-71.

10. Quinn JC, Kiely PD, Lebl DR, Hughes AP. Anterior surgical treatment of cervical spondylotic myelopathy: review article. HSS J. 2015;11:15-25.

11. Chen Y, Chen D, Wang X, Guo Y, He Z. C5 palsy after laminectomy and posterior cervical fixation for ossification of posterior longitudinal ligament. J Spinal Disord Tech. 2007;20:533-5.

12. Lee CK, Shin DA, Yi S, Kim KN, Shin HC, Yoon DH, Ha Y. Correlation between cervical spine sagittal alignment and clinical outcome after cervical laminoplasty for ossification of posterior longitudinal ligament. Neurosurg Spine. 2016;24:100-7.

13. Hirabayashi M, Watanabe K, Wakano K, Suzuki N, Satomi K, Ishii Y. Expansive open-door laminoplasty for cervical spinal stenotic myelopathy. Spine (Phila Pa 1976). 1983:8:693-9.

14. Tokuhashi Y, Ajiro Y, Umezawa N. A patient with two re-surgeries for delayed myelopathy due to progression of ossification of the posterior longitudinal ligaments after cervical laminoplasty. Spine (Phila Pa 1976). 2009;34:E101-5.

15. Odate S, Shikata J, Soeda S, Yamamura S, Kawaguchi S. Surgical results and complications of anterior decompression and fusion as a revision surgery after initial posterior surgery for cervical myelopathy due to ossification of the posterior longitudinal ligament. J Neurosurg Spine. 2017;26:466-73.

16. Sun J, Shi J, Xu X, Yang Y, Wang Y, Kong Q, Yang H, Guo Y, Han D, Jiang J, Shi G, Yuan W, Jia L. Anterior controllable antidisplacement and fusion surgery for the treatment of multilevel severe ossification of the posterior longitudinal ligament with myelopathy: preliminary clinical results of a novel technique. Eur Spine J. 2018;27(6):1469-78.

17. Fujimori T, Iwasaki M, Okuda S, Takenaka S, Kashii M, Kaito T, Yoshikawa H. Long-term results of cervical myelopathy due to ossification of the posterior longitudinal ligament with an occupying ratio of $60 \%$ or more. Spine (Phila Pa 1976). 2014;39:58-67.

18. Fujimori $\mathrm{T}$, Le H, Ziewacz JE, Chou D, Mummaneni PV. Is there a difference in range of motion, neck, and outcomes in patients with ossification of posterior longitudinal ligament versus those with cervical spondylosis, treated with plated laminoplasty? Neurosurg Focus. 2013;35:E9.

19. Katsumi $K$, Izumi $T$, Ito $T$, Hirano $T$, Watanabe H, Ohashi M. Posterior instrumented fusion suppressed the progression of ossification of the posterior longitudinal ligament: a comparison of laminoplasty with and without instrumented fusion by three-dimensional analysis. Eur Spine J. 2016;25:1634-40.

20. Chiba K, Ogawa Y, Ishii K, Takaishi H, Nakamura M, Maruiwa H, Matsumoto M. Toyama Y. Long-term results of expansive open-door laminectomy for cervical myelopathy-average 14-year follow-up study. Spine (Phila Pa 1976). 2006;31:2998-3005.

21. Matsumoto M, Chiba K, Toyama Y. Surgical treatment of ossification of posterior longitudinal ligament and its outcomes: posterior surgery by laminoplasty. Spine (Phila Pa 1976). 2012;37:E303-8.

22. Sakai K, Okawa A, Takahashi M, Arai Y, Kawabata S, Enomoto M, Kato T, Hirai T, Shinomiya K. Five-year follow-up evaluation of surgical treatment for cervical myelopathy caused by ossification of posterior longitudinal ligament: a prospective comparative study of anterior decompression and fusion with floating method versus laminoplasty. Spine (Phila Pa 1976). 2012;37:367-76.

23. Liu H, Li Y, Chen Y, Wu W, Zou D. Cervical curvature, spinal cord MRIT2 signal, and occupying ratio impact surgical approach selection in patients with ossification of the posterior longitudinal ligament. Eur Spine J. 2013;22:1480-8

24. Lee $\mathrm{CH}$, Jahng TA, Hyun SJ, Kim KJ, Kim HJ. Expansive laminoplasty versus laminectomy alone versus laminectomy and fusion for cervical ossification of the posterior longitudinal ligament: is there a difference in the clinical outcome and sagittal alignment? Clin Spine Surg. 2016; 29:E9-E15.

25. Lee $\mathrm{CH}$, Sohn MJ, Lee $\mathrm{CH}$, Choi CY, Han SR, Choi BW. Are there differences in the progression of ossification of the posterior longitudinal ligament following laminoplasty versus fusion?: a meta-analysis. Spine (Phila Pa 1976). 2017:42:887-94

26. Kalb S, Martirosyan NL, Perez-Orribo L, Kalani MY, Theodore N. Analysis of demographic, risk factor, presentation, and surgical treatment modalities for ossified posterior longitudinal ligament. Neurosurg Focus. 2011;30:E11. 
27. Izumi T, Hirano T, Watanabe K, Sano A, Ito T, Endo N. Three-dimensional evaluation of volume change in ossification of the posterior longitudinal ligament of the cervical spine using computed tomography. Eur Spine J. 2013;22:2569-74.

28. Macdonald RL, Fehlings MG, Tator CH, Lozano A, Fleming JR, Gentili F, Berstein M, Wallace MC, Tasker RR. Multilevel anterior cervical corpectomy and fibular allograft fusion for cervical myelopathy. J Neurosurg. 1997;86:990-7.

29. Yamaura I, Kurosa Y, Matuoka T, Shido S. Anterior floating method for cervical myelopathy caused by ossification of the posterior longitudinal ligament. Clin Orthop Related Res. 1999:27-34.

Ready to submit your research? Choose BMC and benefit from:

- fast, convenient online submission

- thorough peer review by experienced researchers in your field

- rapid publication on acceptance

- support for research data, including large and complex data types

- gold Open Access which fosters wider collaboration and increased citations

- maximum visibility for your research: over $100 \mathrm{M}$ website views per year

At $\mathrm{BMC}$, research is always in progress.

Learn more biomedcentral.com/submissions 